\title{
Cross-Linguistic Transfer and Language Proficiency in the Multilingual Education System of Burundi: What has the Existing Literature so far Discovered?
}

\author{
Dominique Savio Nsengiyumva ${ }^{1}$, Celestino Oriikiriza ${ }^{2}$, Sarah Nakijoba3 \\ ${ }^{1}$ Makerere University; Uganda.e-mail: dominiquesavio2014@gmail.com \\ ${ }^{2}$ Makerere University; Uganda.e-mail:oriikiriza@gmail.com \\ 3 Makerere University; Uganda.e-mail: kalyangon1o@gmail.com
}

\begin{tabular}{|c|c|}
\hline ARTICLE INFO & ABSTRACT \\
\hline $\begin{array}{l}\text { Keywords: } \\
\text { cross-linguistic transfer, } \\
\text { multilingual education } \\
\text { system of Burundi, } \\
\text { language curriculum } \\
\text { materials, linguistic } \\
\text { features, language } \\
\text { proficiency }\end{array}$ & $\begin{array}{l}\text { This paper discussed Cross-Linguistic Transfer (CLT) and Language } \\
\text { Proficiency in multilingual education in general and highlighted samples of } \\
C L T \text { in Burundi as the existing literature reveals. As there exist CLT on all } \\
\text { linguistic levels, this discussion has provided examples of phonological } \\
\text { (including phonetics), lexical and semantic, and syntactic transfer. It has been } \\
\text { realized that there exist a limited number of publications related to CLT } \\
\text { among languages studied in the multilingual education system of Burundi. } \\
\text { Yet analyses of CLT would supply interesting samples of linguistic features } \\
\text { that are likely to be transferred. This would be useful for both language } \\
\text { curriculum designers and language policymakers in deciding which language } \\
\text { features to supply in language curriculum materials. Furthermore, teachers } \\
\text { would find ways of helping learners to improve their language proficiency } \\
\text { based on samples of CLT analysis. }\end{array}$ \\
\hline \multicolumn{2}{|l|}{$\begin{array}{l}\text { DOI: } \\
\text { http://dx.doi.org/10.21093 } \\
\text { ijeltal.v5i2.770 }\end{array}$} \\
\hline \multicolumn{2}{|c|}{$\begin{array}{l}\text { How to cite: } \\
\text { Nsengiyumva, D.S., Oriikiriza, C., Nakijoba. S. (2021). Cross-Linguistic Transfer and Language Proficiency } \\
\text { in the Multilingual Education System of Burundi: What has the Existing Literature so far Discovered? } \\
\text { Indonesian Journal of English Language Teaching and Applied Linguistics, 5(2), 387-399 }\end{array}$} \\
\hline
\end{tabular}

\section{Introduction}

To begin, it is crucial to understand multilingual education (some scholars use bilingual education to also mean multilingual education). In the existing literature, there has been plenty of discussions on multilingualism (and or/bilingualism). Some scholars ( $\mathrm{Li}, 2008$; Franceschin, 2011; Cenoz, 2013 and others) view these two concepts as synonymous, whereas others (such as LaMuCuo, 2019, De Groot, 2011) make a clear difference between them. Both multilingualism and bilingualism are usually achieved through formal education. These different forms of education are referred to as multilingual/bilingual education (some 
researchers use the terms bilingual acquisition and multilingual acquisition). A number of researchers (Ortega, 2013, for instance) use multilingual and bilingual education interchangeably while others (García and Lin, 2016, for example) differentiate between these terms.

Among different scholars, bilingual and multilingual education are also viewed in terms of both languages involved and educational contexts. This is the case of contexts in which there is a use of at least two languages for instructions and aiming to produce multilingual speakers (Mwaniki, Arias, and Wiley, 2016). Here, the number of languages in use is as important as the educational contexts. According to Cenoz \& Jasone (1998, viii), multilingual education refers to "educational programmes that use languages other than the first languages as media of instruction (although some teach additional languages as school subjects) and they aim for communicative proficiency in more than two languages". The above perspective tally with the case of Burundi in the sense that a number of languages are taught as the subject instead of being medium of instruction, but the aim is to produce people who will be proficient in those languages.

In the case of the language education system in Burundi, for example, historically, the country has been officially monolingual at a given time. Before missionaries and colonizers introduced their languages, the country was purely monolingual with the use of Kirundi. The country turned into bilingualism with the officialisation of French (especially in education). Later on, more foreign languages (English and Kiswahili) were formally introduced in education. At this time, it can be argued that the country turned into multilingualism. This has mainly been done through the process of formal education which led to the multilingual education system that Burundi has today with four languages in education (i.e. Kirundi, French, English, and Kiswahili).

Based on the history of language in education in Burundi, in this study, multilingual education refers to situations where more than two languages are used in education either as subject or medium of instruction or both at a time. Whereas bilingual education will be understood as contexts where only one foreign language is used in education in addition to the mother tongue.

Generally, bilingual education is different from multilingual education in that during the process of acquiring a (chronological) second language only one language is in the learners' linguistic repertoire while learning an additional (chronological third) language in multilingual education (after the second language has been acquired) may be influenced by both the first and the second language. That is, in bilingual education only two languages interact in the mind of the language learner/user whereas in multilingual education many linguistic systems are in interaction. In both bilingual and multilingual education, there must be interactions between at least two languages in the mind of the learner/user. This has led to the notion of transfer. The next section will discuss cross-linguistic transfer.

\section{Cross-Linguistic Transfer (CLT)}

According to Contrastive Analysis hypothesis, the main hindrance to the learning of L2 is from the interference produced by the L1 system. This has led to the conclusion that differences between $L_{1}$ and $L_{2}$ and misleading similarities were the source of $L_{2}$ learning difficulty. Hence, the notion of transfer. This means that according to Javadi-Safa, (2018, p. 191) "the less the learners know about the $L 2$, the more they need to draw upon any other 
previous linguistic knowledge they possess". Transfer has been believed to proceed in two ways: by inhibiting a linguistic feature that the $L 2$ is trying to process or by facilitating this process. Transfer has been traditionally defined in terms of positive and negative transfer, the latter is also known as interference. For many years, the phenomenon of transfer has been studied by linguists to try to understand the source of $L 2$ learners' errors to the extent that transfer was mainly studying interference. This has led it to get a negative connotation. Late scholars such as Sharwood Smith \& Kellerman (1986) initiated the term cross-linguistic influence which is also interchangeably used with cross-linguistic transfer.

Sharwood Smith \& Kellerman (1986) proposed the term cross-linguistic influence 'as a theory-neutral term that is appropriate for referring to the "full range of ways in which a person's knowledge of one language can affect that person's knowledge and use of another language" (Jarvis\&Pavlenko, 2008, p.2). Among other scholars, Jarvis and Pavlenko decided to use the terms cross-linguistic transfer and cross-linguistic influence interchangeably.

Cross-Linguistic Transfer phenomenon is said to occur when an $L_{2}$ is learned after $L_{1}$. In this situation, the learner will rely on the $L_{1}$ in the process of $L_{2}$ learning. The two existing language systems will most likely interact and have an effect on each other in the mind of the learner (Elvin\&Escudero, 2019; Cenoz, Hufeisen, \& Jessner, 2001). According to these scholars, there is transfer from $L_{1}$ to the $L_{2}$ and vice versa $\left(L_{1} \leftrightarrow L 2\right)$ in the learning of $L 2$. In case the learners are studying an additional language after their chronological $L 2$, this will be referred to as $L_{3}$ Acquisition. The learning of chronological $L_{2}$ and that of $L_{3}$ are two different processes in the sense that the learner learning chronological L2 has only the $L_{1}$ that can interact with L2. In the learning of $L_{3}$ the number of background languages is higher, therefore posing the possibility of "interactions among a multiplicity of different linguistic systems" which is more complex (Bardel, 2015, p.116). These interactions can take any direction i.e. $L_{1} \leftrightarrow L_{2}, L 1 \leftrightarrow L 3, L 2 \leftrightarrow L 3$ (Cenoz, Hufeisen, and Jessner, 2001; Jarvis and Pavlenko, 2008).

In the case of Burundi, for example, there are four languages being learned at the same time: Kirundi, French, English, and Kiswahili. These are different linguistic systems that are being processed in the mind of learners at the same time. There is a need to investigate how these systems interact in different directions through the analysis of learners' language production and comprehension.

\section{Cross-linguistic Transfer and Language proficiency}

Based on the observation of Odlin (1989) cited in Jarvis and Pavlenko, (2008) that "transfer can occur in all linguistic subsystems" (p. 23), this section discusses aspects of the CLT on different linguistic levels in order to track language proficiency through the analysis of language transfer. The main linguistic levels discussed in the literature are phonological transfer, Lexical and Semantic Transfer, and Syntactic Transfer. The discussion also shows how proficiency is viewed at different levels and different groups of language learners/users as far as CLT is concerned.

\subsection{Phonological Transfer}

For different researchers, the term phonological transfer can be generally used to denote how a person's language knowledge of the sound system of one language can have an influence on his/her perception and production of speech sounds in another. According to 
Jarvis and Pavlenko, (2008) phonological transfer can cover other terms for several CLT phenomena, including L2 users sounds perception and production (i.e., phonetics), and their techniques of classifying, structuring, and organizing these sounds (i.e., phonology).

Among scholars who explored phonological transfer include, Lipińska (2015) who studied the production of vowels by $L_{3}$ users arguing that $L_{3}$ sounds production might be a much more complex process than $L_{2}$ sound production. The author studied $L_{3}$ segmental production in the directions as $L_{1}$ to $L_{3}$, $L_{2}$ to $L_{3}$ or $L_{3}$ intra-lingual interference. However, these are not the only directions that the influence can take. In fact, a natural investigation on any direction of transfer as this occurs would provide more comprehensive results. As the Burundi's multilingual system has got four languages, there is a possibility to investigate, at the phonological level, how these languages interact by analysing cross-linguistic transfer.

Adrián, Puerto, and Mangado (2013) studied transfer of errors at phonetics and syntax levels among younger learners in the school context. They found that the main transfer errors were at phonetic level including replacement of novel phonemes by L1 sounds, spirantisation and lack of aspiration in stop sounds, closure of fricatives. These studies support the idea that the more a learner advances in proficiency, the less transfer occurs.

In the literature, there is a limited number of studies on the most obvious phonetic features produced by L2 users or learners. That is, the production of target language sounds the same way these sounds would be produced in their $L_{1}$ because those $L_{2}$ sounds do not exist in the learners' $L 1$. This is also true for the phonological production in written form. When teachers give dictation in a foreign language, learners tend to transfer their L1 phonemes to the target language. Nevertheless, Harding, (2000) has found that different types of spelling errors are determined by learners' different L1 backgrounds. According to the author, these transfer effects are also most frequent among lower-level proficiency learners because they are less familiar with the L2 orthography and lexicon.

Sound production and syllable structure, however, have received limited discussions about the significant difference between sounds production (phonetics) and code related skills and decoding (phonology), and how these features might lead to different degrees of transfer and, therefore to different degrees of proficiency among different groups of language learners/users. Moreover, amongst studies on phonological/phonetic transfer, very few have explored different directions on different groups of learners (But see Gut, 2008). Most of these studies focussed on simultaneous language acquisition among bilingual children (Verhoeven, 2007; Soltero-Gonzalez, Escamilla and Hopewell, 2011; Fabiano-Smith and Goldstein, 2010; Yang \& Fox, 2014; Lee and Iverson, 2012) not sequential language learners to illustrate differences between these categories of learners (but see Commissaire, Duncan and Casalis, 2011 for the contrary).

\subsection{Lexical and Semantic Transfer}

Lexical knowledge has to do with the knowledge of words. This includes the form and the meaning sides of words. According to Bardel (2015, p.115) "words are interconnected in the human mind in a complex web of formal, semantic and pragmatic connections." As lexis is the knowledge of a language words, lexical CLT, is the interaction among words of different languages a person knows or uses. Past and current research on lexical CLT support that words a person knows in different languages are interconnected in the mind. This means that 
it is easy that a person's knowledge of words in one language affects the learning, processing, and use of words of another or other language(s) in the person's repertoire. Bardel (2015) distinguishes two types of lexical CLT: formal CLT (transfer of form) and meaning-based CLT (transfer of meaning).

One of the formal cross-linguistic transfer is code-switch as in this example (from Bardel, 2015) in which the speaker switches into Swedish while trying to tell the story into French: Je viens seulement a ' la lection (source: Swedish: lektion). English: I only come to the lesson (target word: leçon). This type of CLT is manifest when a target-language word with a specific meaning reflects the influence from the meaning of an analogous word in another language in the users' repertoire. Suherman, Indrayani and Krisnawati (2020) have studied EnglishIndonesian interlanguage and realized English learners (L2) produce English morphological structures classified in Suppliance, non-suppliance and over-suppliance with overgeneralization of English rules as the most dominant factors of interlanguage variation in the English language produced by these learners.

In her study of CLT among Spanish and Italian learners, Bardel (2015, p. 119) found that there are various instances of CLT that were referred to as "lexical innovations". Other findings of CLT manifestations concerned with overgeneralization and back-formation which affected all Spanish and Italian learners regardless of their $L 1$.

Example of foreignizing in a student's L1Spanish:

People instead of worrying about their problems, they refugiated ...

Examples of overgeneralization of - (at) ion:

(...) will be the epoque of peace and world cooperation aimed at better solvation of numerous problems of humanity. (English: solve $\rightarrow$ solution)

Example of back-formation as a result from the application of an L2-based strategy in students pieces of writing:

They are always looking for some ideal, dreaming about it imaginating it. (English: imagine; back-formation from imagination)

Cross-linguistic transfer also occurs at semantic level, such as in the following example: the polysemous word rum (meaning either room, bedroom, or office) in Swedish matches either 'chambre' or 'bureau' in French.

Elle a trouvé les valises dans dans dans une chambre qui n'était pas fermée (here the target word was bureau) ('She found the suitcases in in in a bedroom that was not closed')

This has been referred to as semantic extension whereby the learners use their Background Languages $(B L)$ for their transfer strategies as observed by (Bardel, 2015. p, 119).

According to Ringbom (2001), semantic transfer is not just from any earlier learned language, but it is mostly L1. This is highly connected to the learners' proficiency in the L2. The L1 meanings of words have a tendency to underlie L2 words until the learner becomes highly proficient in their L2. When a learner is highly proficient in the target language, semantic influence can then result from that target language. On the semantic CLT, it has been argued that CLT has an effect not just on a language a learner has not yet adequately acquired, even advanced adult L2 learners (known as late bilinguals) who are actually highly proficient in 
their $L_{1}(s)$ can produce lexical errors in their L1s. This is a reflection of semantic CLT effects from the learners' L2(s). This is known as reverse semantic CLT.

However, in her study on formal CLT, Lindqvist (2009) found that the more students are advanced and have enough proficiency in the target language, the lower proportion of these types of CLT they have. Conversely, other studies (De Angelis, 2007; Ringbom, 2007) show that different types of CLT occur as the learners reach a higher level of proficiency in the target language. This is the case of semantic CLT. Furthermore, low proficiency in different languages known by the learner (referred to as background languages) can also be the source of CLT. In their study, Bardel \& Lindqvist (2007) found that the low proficiency in Italian (L3 $\mathrm{TL}$ ) was associated with CLT from Spanish (learner's L2) low-proficiency as a background language. Some studies about lexical and semantic CLT agree on the fact that proficiency is associated with CLT occurrences.

\subsection{Syntactic Transfer}

In the past, researchers have considered that Syntax (like morphology) is not subject to transfer. However, recent studies have shown instances of syntactic transfer in different forms of data. This kind of CLT occurs in different directions. Altenberg, (1991) and Köpke, (2002) argue that learning a second language can lead a person to be tolerant of ungrammatical productions in his/her L1. Also, the person can reject $L_{1}$ sentences that are seen as perfectly grammatical by peer native speakers who are monolingual. Some studies have concluded that syntactic CLT frequently occurs when learners have low proficiency in their target language. Those learners with higher levels of target language proficiency rely less on their L1.

For instance, Alonso (2002) studies learners' interpretation of $L 2$ sentences and found that these students relied less on their $L 1$ as their $L 2$ proficiency increased. And later on, when they were tested on their L1S, these learners relied more on L2 because their L2 proficiency had significantly increased. On the contrary, Lindqvist and Falk, (2014) studied lexicon and syntax among learners of French as their L3. They found that $96 \%$ of the occurrences of syntactic transfer came from the learners L2S (in which learners have low proficiency compared to their L1S), concluding that syntactic transfer comes from L2 not L1.

Linarsih, Irwan, and Putra (2020) studied the interferences of Indonesian grammatical aspects into English by preservice English Teachers' learning EFL. They realised four types of English subject-verb agreement patterns which revealed transfer from the Indonesian language. Therefore, confirming the role of $L_{1}$ in the learning of English as a Foreign Language.

Studies arguing that proficiency in a background language is useful for the learning of the target language do not specify how much $L_{1} / L_{2} 2$ experience is needed before benefits for $L_{3}$ development begin. Also, they do not explicate how much experience would allow the target language in order to also influence the production of previously acquired languages or about whether transfer effects depend on the type of the target language instructions, students' background, or whether the languages are simultaneously or sequentially acquired. Most of these studies are quantitative studies that do not show instances of what were transferred and analyse through these examples how these CLT effects occurred. 


\section{Cross-Linguistic Transfer in the Multilingual Education System of Burundi}

As it has been discussed earlier, Burundi has a multilingual education system. That is four languages in the educational system of Burundi. If one could map language education in Burundi, it could be said that these languages that are in formal education are also used in the people's every day communication. Most of the people have learned these languages in formal education (especially French and English), but others picked the languages in everyday use from neighbours, friends, classmates. This is the case of Kiswahili, for example. Note that a considerable number of people has lived in Tanzania (a neighbouring country) due to different reasons. Since this discussion targets languages as they are learned in classroom, it is vital to give an overall picture of these languages showing the current grade where the languages are studied and the time that is allotted to each of the languages.

To see the languages and the time allotted to each of them in Burundi education today (from grade 1 to the end of secondary school), consult the table below:

Table 1: Time Allocation for Languages from Primary through Secondary Education in Burundi Public Schools (2019-2020)

\begin{tabular}{|c|c|c|c|c|c|c|c|}
\hline $\begin{array}{c}\text { Language/ Number of } \\
\text { hours per week }\end{array}$ & Grade 1 & Grade 2 & Grade 3 & Grade 4 & Grade 5 & Grade 6 & Total \\
\hline Kirundi & 22 & 8 & 5 & 4 & 4 & 3 & 46 \\
\hline French & 11 & 8 & 9 & 9 & 9 & 5 & 51 \\
\hline English & 0 & 2 & 2 & 2 & 2 & 3 & 11 \\
\hline Kiswahili & 0 & 4 & 2 & 4 & 4 & 3 & 17 \\
\hline \multicolumn{8}{|c|}{ Basic Education (Extension of Primary Education) } \\
\hline Language/ Number & $\mathrm{F}_{1}$ & $F_{2}$ & $\mathrm{~F}_{3}$ & & & & \\
\hline \multicolumn{8}{|l|}{ of hours per week } \\
\hline Kirundi & 2 & 2 & 2 & & & & 6 \\
\hline French & 5 & 5 & 5 & & & & 15 \\
\hline English & 5 & 5 & 5 & & & & 15 \\
\hline Kiswahili & 1 & 1 & 1 & & & & 3 \\
\hline \multicolumn{8}{|c|}{ Secondary Education: Languages and Social Sciences Section } \\
\hline & PF1 & $\mathrm{PF}_{2}$ & $\mathrm{PF}_{3}$ & $\mathrm{PF}_{4}$ & & & \\
\hline Kirundi & 4 & 4 & 4 & & & & 12 \\
\hline French & 10 & 10 & 10 & & & & 30 \\
\hline English & 10 & 10 & 10 & & & & 30 \\
\hline Kiswahili & 5 & 5 & 5 & & & & 15 \\
\hline \multicolumn{8}{|c|}{ Sciences A/and B } \\
\hline Kirundi & 1 & 1 & 1 & & & & 3 \\
\hline French & 2 & 1 & 1 & & & & 4 \\
\hline English & 2 & 1 & 1 & & & & 4 \\
\hline Kiswahili & 1 & 1 & 1 & & & & 3 \\
\hline \multicolumn{8}{|c|}{ Teacher Training Section } \\
\hline Kirundi & 2 & 2 & 2 & 1 & & & 7 \\
\hline French & 3 & 2 & 2 & 1 & & & 8 \\
\hline English & 3 & 2 & 2 & 1 & & & 8 \\
\hline Kiswahili & 2 & 1 & 1 & 1 & & & 5 \\
\hline
\end{tabular}


As it can be seen from this table, Kirundi, as a mother tongue is focussed on especially in the first grade of primary education. However, it loses time as pupils move to the next grade. The loss of hours for the mother tongue gives space to French, which later becomes the language of instruction. But at the secondary education level, French and English take a considerable amount of time. This table only highlights languages as they are used in public schools. Private schools have different schedules, and mostly foreign languages such as French and English take more time depending on whether the school is using French or English as a medium of instruction.

Besides the current picture of languages in education as of today, there is a need to understand how the country got there. In fact, sometimes the languages are used as medium of instruction whereas others are taught as subjects (i.e., in education in public schools). Since in public schools, only French is used a medium of instruction from grade five primary education, the evolution of languages used as either medium of instruction or taught as subject will therefore be shown at the primary level.

Table 2: Evolution of Language in Burundi Education at the primary level (adapted from CNDIH, 2014)

\begin{tabular}{|l|l|l|}
\hline Period & Language of Instruction & Language Subject \\
\hline $1961-1973$ & $\begin{array}{l}\text { Kirundi in grade 1 and French } \\
\text { from grade 2 }\end{array}$ & $\begin{array}{l}\text { Kirundi on the whole curriculum and French from } \\
\text { grade 2 }\end{array}$ \\
\hline $1973-1988$ & $\begin{array}{l}\text { Kirundi from grade 1 to grade 4 } \\
\text { and French from grade 5 }\end{array}$ & $\begin{array}{l}\text { Kirundi on the whole curriculum and French from } \\
\text { grade 3 }\end{array}$ \\
\hline 1989-2005 & $\begin{array}{l}\text { Kirundi from grade 1 to grade 4 } \\
\text { and French from grade 5 }\end{array}$ & $\begin{array}{l}\text { Kirundi on the whole curriculum and French from } \\
\text { grade 1 }\end{array}$ \\
\hline 2006-2017 & $\begin{array}{l}\text { Kirundi from grade 1 to grade 4 } \\
\text { and French from grade 5 }\end{array}$ & $\begin{array}{l}\text { Kirundi throughout the curriculum and French, } \\
\text { English and Kiswahili from grade 1 }\end{array}$ \\
\hline 2018-Present & $\begin{array}{l}\text { Kirundi from grade 1 to grade 4 } \\
\text { and French from grade 5 }\end{array}$ & $\begin{array}{l}\text { Kirundi throughout the curriculum and French from } \\
\text { grade1, English and Kiswahili from grade } 2\end{array}$ \\
\hline
\end{tabular}

This table shows that as time went on, there has been the introduction of different foreign languages in education, from only French being a foreign language to having four foreign languages that pictures the actual situation in Burundi multilingual education system at primary level. These languages have not only created multilingual individuals but also multilingual society.

Having in mind the pictures of language in the multilingual education system of Burundi, the main intention in this discussion is to discover how these languages interact in the mind of the learners. The objective of the present debate is to discover what literature has so far achieved in studying CLT in the multilingual education system of Burundi. The next paragraphs are going to highlight examples found in the literature as far as Crosslinguistic transfer and language proficiency is concerned in the multilingual education system of Burundi.

Sikogukira (1993) studied the influence of languages other than the L1 on a foreign language by looking at lexical transfer from $L 2$ to $L 3$ with focus on French-English cognates among Burundi university students. He found that the participants transferred mostly non-cognate 
English words which are in a relation of either synonymy or hyponymy with the FrenchEnglish cognates in question. For example, in this study, among transferred pairs, veterinary was taken for 'veterinarian' because they both have the same French equivalent 'véterinaire' and was highly rated by all the groups as synonymous; estimate was confused with 'esteem' because they share the same French equivalent 'estimer'. However, the tendency of accepting or rejecting the use of the cognates, decreased with the increase in the participants' level of proficiency.

In addition, Nkeshimana (2016) conducted a classroom observation to explore interactions between languages taught. He realised that in a dictation given to students, many words were wrongly spelt despite the appropriate pronunciation from the teacher. In this case, there are both the influence of $L_{1}$ and $L_{2}$ at the phonological transfer. The example of 'of cause' instead of 'of course' is a transfer from French. In addition, 'wesiday' and 'fesiday shows a transfer from both Kirundi and French. The $[\mathrm{f}]$ instead of $[\theta]$ in 'Thursday' is from Kirundi. The Kirundi $[\mathrm{f}$ ] is stronger than the English [ $\theta$ ], which leads to to Kirundi [f] being selected by the learner at lower level of English performance. There is also influence of $L 1$, such as in 'why' spelt as 'wayi'. In Kirundi, no word can end in a consonant. This brings the tendency to put a vowel (such as [i] in this case) at the end of words ending in consonants from other languages and to separate consonant cluster [wh], which does not exist in Kirundi which makes the word a two-syllable word in Kirundi instead of one syllable word of English.

Examples: Wednesday $\rightarrow$ wesiday
Thursday $\longrightarrow$ fesiday
Of course $\longrightarrow$ of cause,
Monday $\longrightarrow$ manday
Why $\longrightarrow$ wayi
Thankyou $\longrightarrow$ fenkyou
The $\longrightarrow$ de

Kavyinirwa (2012) also found that students confuse languages. They do not know which language to use when they reply to teachers' questions because their minds activate these languages at a time. This raise the question of how many languages can be taught at a time at which stage of the children development, or in other words, how many languages can the mind of a child process and differentiate at a time. It seems that children are exposed to too many languages very early. Theorists say that in matters of acquiring a new language, the earlier, the better. But the case of Burundi shows that it is not always practical to expose children to many languages at a time even though it might be early.

In the following example, the pupils are asked in English, but some reply in in French, others in Kiswahili. This shows to what extend the different languages that these pupils are exposed to are hardly processed, which leads to confusion.

Teacher : what is your name?

Pupils : je m'appelle... (French)/ Jina langu.... (Kiswahili) 
On his side, Nduwimana (2013) observed language classes both in urban and rural areas where the language being taught was English. He realised that teachers use French or Kiswahili to teach English (code-switching) in urban area whereas they use Kirundi in codeswitching in the rural area. The languages of codeswitching depend on the languages of the environments where students and teachers are from.

Ndayipfukamiye (1996) also examined language practices in schools in rural and urban areas of Burundi. The teacher interchanged frequently between Kirundi and French in order to handle communicative challenges and to check on learners' understanding. Here is an example of extracts of the classroom observations recordings:

T: On dit qu'on prend ses feuilles pour faire des... pour faire des toits. Vous avez été a I'interieur? hanyuma hari ivyo bariko barwaganya vyitwa hein .donc eh ubu biriko birahera mugabo kera ugiye wasanga inzu zose zisakaje ivyatsi. ivyatsi. hamwe wasanga ari ubgatsi vyo mw'ishamba. ahandi ugasanga ari ubgatsi? 'It is said that its leaves [the leaves of a tree] are used to cover roofs. Have you already been in the countryside? There is a practice that is being combated called thatched rooting err... and so the practice is now receding but in the past, all the houses were covered in thatch ... thatch. it was forest foliage, and in other instances what could you find?'

Both Teachers, that is, the teacher in the urban area, and the teacher in the rural school code switched frequently between French and Kirundi while they were explaining one particular aspect of traditional house-building practices: the use of Nyakatsi "thatched roofing." The teachers alternated between Kirundi and French throughout the lesson. At this time, there was no English and Kiswahili in education at this level. This is where bilingual instead of multilingual education needs to be discussed in a historical perspective. The only possibility of code-switching was French and Kirundi, and transfer could only occur between Kirundi and French.

According to Varly \& Mazunya (2018) Kirundi and French have pedagogical advantages as they share the Latin alphabet. However, at the morphosyntactic level, Kirundi is a synthetic language, whereas French is rather analytical, which may be the basis of difficulties related to the learning of its spelling. Existing textbooks do not emphasize those aspects of linguistics that would allow teachers to identify the origin of their pupils' faults and then adopt appropriate pedagogy for the treatment of linguistic interference.

As can be seen in this discussion, there are a few instances of cross-linguistic transfer as shown by the scanty literature on language in Burundi education system. However, the literature on CLT effect in Burundi multilingual education rarely discusses the issue. This shows how the notion of cross-linguistic transfer among languages learned in Burundi has poorly been accounted for. There is no systematic analysis of CLT effect on different linguistic levels discussed in previous sections, such as phonological, lexical and semantic, syntax or morphosyntax that can inform language proficiency, especially its degenerating aspect. There is a need for an investigation that extend this aspect of multilingual education not only to the actual situation but across time. Burundi has had a bilingual system in education, and today, it operates in a multilingual education system, but studies about these linguistic circumstances are almost inexistent. Yet, these linguistic aspects might be the root source of the deteriorating proficiency observed among languages learned in the multilingual system of Burundi. 


\section{Conclusion}

As has been observed by Mazunya and Habonimana (2010), there exist a limited number of publications related to linguistic orientations or involving internal and external effectiveness of languages taught in Burundi. The examples that have been given here show that the only Crosslinguistic transfer analyses have been done by either the university lecturers or students. There are no other scholars that have found interest in studying how these languages found in education in Burundi interact and how the effects of interaction on students' language proficiency. Yet this would supply interesting samples of linguistic features that are likely to be transferred, which would be useful for both language curriculum designers and teachers.

On the one hand, language curriculum designers and language curriculum policymakers would be informed on what linguistic aspects to focus on in the design of the textbooks specific to groups of students. This would allow them to ensure these linguistic aspects can improve the students' proficiency. To achieve this, language curriculum designers and language curriculum policymakers would look at the interactions that are likely to occur among these languages and use them as an asset. Instead of being a hindrance for students' improvement of their proficiency, these interactions become a source of improvement in the language teaching materials that are produced. On the other hand, language teachers would find factual illustrations of linguistic features that trouble specific groups of students. This will allow the teachers to find a way to provide their students with appropriate assistance to improve their language proficiency.

\section{Acknowledgments}

This paper is part of a Ph.D. research project with funding from the Gerda-Henkel Stiftung Foundation at the College of Humanities and Social Sciences of Makerere University.

\section{REFERENCES}

Adrián, M. M., Puerto, F. G., \& Mangado, J. G. (2013). Phonetic and syntactic transfer effects in the English interlanguage of Basque/Spanish bilinguals. Vigo International Journal of Applied Linguistics, (10), 51-83.

Alonso M. R. (1997): Language Transfer Interlingual Errors in Spanish Students of English as a Foreign Language. Revista Alicantina de Estudios Ingleses. 10 7-14

Altenberg, E. (1991). Assessing first language vulnerability to attrition. In H. Seliger \& R.Vago (Eds.), First Language Attrition (pp. 189-206). Cambridge, UK: Cambridge University Press.

Bardel, C. (2015). Lexical cross-linguistic influence in third language development. Transfer effects in multilingual language development, 4, 117-128.

Bardel, C., \& Lindqvist, C. (2007). The role of proficiency and psychotypology in lexical crosslinguistic influence. A study of a multilingual learner of Italian L3. In Atti del VI Congresso di Studi dell'Associazione Italiana di Linguistica Applicata (pp. 123-145). Perugia: Guerra Editore. 
Cenoz, J. (2013). The influence of bilingualism on third language acquisition: focus on multilingualism. Language Teaching (46)10, 71-86

Cenoz, J., \& Genesee, F. (Eds.). (1998). Beyond bilingualism: Multilingualism and multilingual education (Vol. 110). Multilingual Matters.

Cenoz, J., Hufeisen, B., \& Jessner, U. (2001). Cross-linguistic influence in third language acquisition: Psycholinguistic perspectives (Vol. 31): Multilingual Matters.

Commissaire, E.; Duncan, L.G. (2011), Cross-language transfer of orthographic processing skills: a study of French children who learn English at school. Journal of Research in Reading, ISSN 0141-0423 DOI: 10.1111/j.1467-9817.2010.01473.x (34) 1, 59-76

Commission Nationale Indépendante des Droits de I'homme (CNIDH) (2014). Les Réformes du Système Educatif Burundais et le Droit à l'éducation. Bujumbura

De Angelis G. (2007). Third or additional language acquisition. Multilingual matters

De Groot, A. (2011). Language and Cognition in Bilinguals and Multilinguals: An Introduction. Psychology press.

Elvin, J., \& Escudero, P. (2019). Cross-Linguistic Influence in Second Language Speech: Implications for Learning and Teaching. In Cross-Linguistic Influence: From Empirical Evidence to Classroom Practice (pp. 1-20): Springer.

Franceschini, R. (2011). Multilingualism and Multicompetence: A Conceptual View The Modern Language Journal, (95)3, 344-355

García, O. and Lin, A. (2016). Extending Understandings of Bilingual and Multilingual Education. Bilingual and Multilingual Education.1-20

García, O., \& Lin, A. (2017). Extending understandings of bilingual and multilingual education. Bilingual and multilingual education, 1-20.

Jarvis S., Pavlenko A. (2008). Crosslinguistic Influence in Language and Cognition. Routledge Javadi-Safa, A. (2018). A Brief Overview of Key Issues in Second Language Writing Teaching and Research. International Journal of Education and Literacy Studies 6(2), 12-25.

Kavyinirwa, B. (2012). Les Effets de l'Introduction de l'Anglais et du Kiswahili sur L'Enseignement Apprentissage des Language Etrangères au Burundi: Enquêtes Menées dans les Ecoles Primaires de la Commune Bisoro. BA Dissertation, Université du Burundi, Bujumbura.

Köpke, B. (2002). Activation thresholds and non-pathological first language attrition. In Fabbro, F. (Ed.), Advances in The Neurolinguistics of Bilingualism (pp. 119-142).

LaMuCuo, Y. (2019). Becoming Bilingual in School and Home in Tibetan Areas of China: Stories of Struggle. Multilingual Education. Switzerland

Leah Fabiano-Smith.Goldstein P.B. (2010). Phonological Acquisition in Bilingual SpanishEnglish Speaking Children Journal of Speech, Language, and Hearing Research. (53)160178

Lee, S.A. \& Iverson G. K. (2012). Bilingualism: Language and Cognition, 15. 275 - 287. doi:10.1017/S1366728911000083

Li, W. (2008). Research perspectives on bilingualism and bilingual education. Springer

Linarsih, A., Irwan, D., \& Putra, M. I. R. (2020). The Interferences of Indonesian Grammatical Aspects into English: An Evaluation on Preservice English Teachers' EFL Learning. Indonesian Journal of English Language Teaching and Applied Linguistics, 5(1), $69-81$. 
Lindqvist C., Bardel C. (2007). The role of proficiency and Psychotypology in lexical crosslinguistic influence. A study of a multilingual learner of Italian L3. Proceedings of the VI Congress of Studies of Italian Association of Applied Linguistics, 123-145, 2007

Lindqvist, C. (2009). The use of the L1 and the L2 in French L3: examining cross-linguistic lexemes in multilingual learners' oral production. International Journal of Multilingualism, 6(3), 281-297.

Lindqvist, C., \& Bardel, C. (2014). Exploring the impact of the proficiency and typology factors: Two cases of multilingual learners' L3 learning. In Essential topics in applied linguistics and multilingualism (pp. 253-266). Springer, Cham.

Lipinska D. (2015). Production of $L_{3}$ vowels: is it possible to separate them from $L_{1}$ and $L_{2}$ sounds? Research in Language, 13(10), 77-92.

Mwaniki, M., Arias, M. B. and Wiley T.G. (2016). Bilingual Education Policy. Bilingual and multilingual education, 35-49

Ndayipfukamiye, L. (1996). The contradictions of teaching bilingually in post-colonial Burundi: From Nyakatsi to Maisons en Etage. Linguistics and Education, 8(1), 35-47.

Nduwimana, F. (2013). A Comparative Study of the Problems Encountered in the Teaching of English to Rural and Public Primary Schools: Cases of First and Second Grades Kayanza Province and Bujumbura Municipality. BA Dissertation, Université du Burundi, Bujumbura.

Nkeshimana, C. (2016). Problems Encountered in the Teaching of Writing Skills by Learners in Rural Areas: A Case Study of $6^{\text {th }}$ Form Students in Selected Secondary Schools of Gitega Province, 2014-2015. BA Dissertation, Université du Burundi, Bujumbura.

Ortega, L. (2013). Understanding Second Language Acquisition. Routledge. New York

Ringbom, H. (2001). Lexical Transfer in L3 Production. In J.Cenoz, B. Hufeisen, \& U. Jessner (Eds). Cross-Linguistic Influence in Third Language Acquisition: Psycholinguistic Perspective. Multilingual Matter.

Sikogukira, M. (1993). Influence of Languages Other than the L1 on a Foreign Language: A Case of Transfer from L2 to L3. Edinburgh Working Papers in Applied Linguistics 4(110-132)

Soltero-González, L., Escamilla, K\& Hopewell, S. (2012) Changing teachers' perceptions about the writing abilities of emerging bilingual students: towards a holistic bilingual perspective on writing assessment. International Journal of Bilingual Education and Bilingualism. (15)1, 71-94, DOI: 10.1080/13670050.2011.604712.

Suherman, R., Indrayani, L. M., \& Krisnawati, E. (2020). Portraying the English Morphological Development of Indonesian-English Interlanguage Learners. IJELTAL (Indonesian Journal of English Language Teaching and Applied Linguistics), 5(1), 83-96.

Varly, P. \& Mazunya, M. (2018). Report on the Quality of Education. Burundi ASA (P161127) Verhoeven L. (2007). Early Bilingualism, Language Transfer, and Phonological Awareness Applied Psycholinguistics (28), 425-439. DOI: 10.1017. So142716407070233

Yang J., Fox, R.A. (2014). Acoustic properties of shared vowels in bilingual Mandarin-English children. INTERSPEECH. Fifteen Annual Conference of the International Speech Communication Association 